\title{
FOSSILDIAGÊNESE E GEOQUÍMICA DOS CRUSTÁCEOS DECÁPODES DA FORMAÇÃO MARIA FARINHA (PALEOCENO), ESTADO DE PERNAMBUCO, BRASIL
}

\author{
VLADIMIR DE ARAÚJO TÁVORA ${ }^{1}$, FABRÍCIO ARAÚJO DA SILVA ${ }^{1,2}$ \& \\ EDUARDO DE JESUS SOUZA ${ }^{2}$
}

\begin{abstract}
FOSSILDIAGENESIS AND GEOCHEMISTRY OF THE DECAPOD CRUSTACEAN OF THE MARIA FARINHA FORMATION (PALEOCENE), PERNAMBUCO/PARAIBA BASIN, PERNAMBUCO STATE, BRAZIL This study includes fossildiagenetical and geochemical analysis of the decapod carapaces and the host rocks, sampled at the Poty quarry, outcrop of the Maria Farinha Formation, State of Pernambuco, Brazil. In this geological setting the brachyura are envolved by biomicrites mineralogically composed by quartz, calcite, hidroxylapatite, dolomite and kaolinite. The allocheme elements in these biomicrites are represented by decapod crustaceans, benthonic and planktonic foraminifera, ostracods, microbivalves, microgastropods, calcareous algae, microbryozoans, corals, diatoms and spines of echinoids. Six presumebly simultaneous eodiagenetic processes were identified: (1) replacement of the skeletal aragonite by calcite; (2) pyritization of the organic matter; (3) phosphatization of the organic matter; (4) mechanical compactation; (5) formation of $\mathrm{CaCO} 3$ fringe; and (6) local dissolution of $\mathrm{CaCO} 3$ precipitated in pores. The $\delta 13 \mathrm{C}$ e $\delta 18 \mathrm{O}$ values suggested marine palaeoenvironment with high oxidation of the organic matter in the benthos during times of the low sea level and the continental influence.
\end{abstract}

Keywords: Fossildiagenesis, Geochemistry, Maria Farinha Formation, Paleocene.

Resumo Este trabalho compreende o estudo fossildiagenético e geoquímico-análise química qualitativa e análise da composição dos isótopos estáveis de Carbono e Oxigênio, em carapaças de crustáceos decápodes e rochas que os contém, procedentes da Pedreira Poty, afforamento natural da Formação Maria Farinha. Os braquiúres em seu contexto geológico estão encerrados em biomicritos sem variações texturais e composicionais, constituídos mineralogicamente por quartzo, calcita, hidroxilapatita, dolomita e caolinita. Nestes calcários são freqüentes como elementos alóquemes, foraminíferos bentônicos e planctônicos, ostracodes, microbiválvios, microgastrópodes, algas calcárias, microbriozoários, corais, diatomáceas e espinhos de equinóides, além dos crustáceos decápodes. Foram identificadas seis fases eodiagenéticas, possivelmente simultâneas: substituição da aragonita esqueletal por calcita, piritização da matéria orgânica, fosfatização da matéria orgânica, compactação mecânica, formação de franja de $\mathrm{CaCO} 3$ e dissolução local do $\mathrm{CaCO} 3$ já precipitado nos poros. Os valores de $\delta 13 \mathrm{C}$ e $\delta 180$ indicam paleoambiente deposicional marinho com alta taxa de oxidação da matéria orgânica no benthos em períodos de rebaixamento do nível do mar, com influência continental.

Palavras-Chave: Fossildiagênese, Geoquímica, Formação Maria Farinha, Paleoceno.

INTRODUÇÃO A associação de crustáceos decápodes da Formação Maria Farinha é composta por Dardanus fucosus Biffar \& Provenzano, 1972 e D. insignis (Saussure, 1858)- pagurídeos, Calianassa fragilis Biffar, 1971, Protocalianassa archiaci (Milne-Edwards, 1860), Upogebia affinis Say, 1818 e Ctenocheles hutchinsoni Rodrigues, 1978- calianassídeos, e Costacopluma nordestina Feldmann \& Martins-Neto, 1995- retroplumídeo, Necrocarcinus sp.- calapídeo, e Glyphithyreus sturgeoni Feldmann et al., 1998- goneplacídeo, todos tipicamente marinhos de águas rasas ou de zonas intermarés, viventes em longas e profundas cavidades escavadas em sedimentos arenosos ou argilosos, e também sobre o substrato (pagurídeos).

O registro fossilífero destes crustáceos é bastante comum, apesar das restrições tafonômicas causadas pelo seu ambiente de vida (que não é muito propício à acumulação de tanatocenoses, devido a alta intensidade dos processos de erosão e retrabalhamento) e, a baixa calcificação das carapaças- isso nos calianassídeos e pagurídeos. No Brasil, estes táxons são reconhecidos apenas nos sedimentitos paleocênicos da Formação Maria Farinha.

O trabalho em questão, objetiva a realização de estudos fossildiagenéticos e geoquímicos da paleocarcinofauna, através de diversas técnicas, incluindo estudos petrográfico e diagenético, análises químicas quantitativas dos elementos principais ( $\mathrm{SiO} 2$,
Al2O3, Ferro total, TiO2, P2O5 e perda ao fogo), absorção atômica ( $\mathrm{CaO}, \mathrm{MgO}$ e $\mathrm{Mn}$ ), investigação dos isótopos estáveis de Carbono e Oxigênio e, difratometria de raios-x (para caracterização da mineralogia).

GEOLOGIA A bacia Pernambuco-Paraíba localiza-se no nordeste do Brasil, na região costeira e na margem continental dos estados da Paraíba e Pernambuco e, na porção oriental do Rio Grande do Norte. Possui uma coluna sedimentar incompleta em relação às outras bacias marginais (Muniz,1993), onde faltam evaporitos da fase proto-oceânica e a espessa seção clástica da fase marinha franca, que se exibem nas outras bacias da margem continental brasileira.

Estudos recentes na bacia Pernambuco-Paraíba resultaram na definição do limite Cretáceo-Terciário com base em dados paleontológicos (Mabesoone et. al. 1968, Albertão et. al., 1993, 1994), além de análises geoquímicas, que mostraram uma anomalia de irídio significativa. Tal limite situa-se a cerca de 40 $\mathrm{cm}$ acima do contato litológico entre as formações Gramame e Maria Farinha na Jazida Poty e, portanto incluído na Fomação Maria Farinha.

A Formação Maria Farinha possui uma grande variabilidade litológica, caracterizando-se por uma seqüência de calcários fossilíferos detríticos com estratificação plano paralela. $O$ perfil 


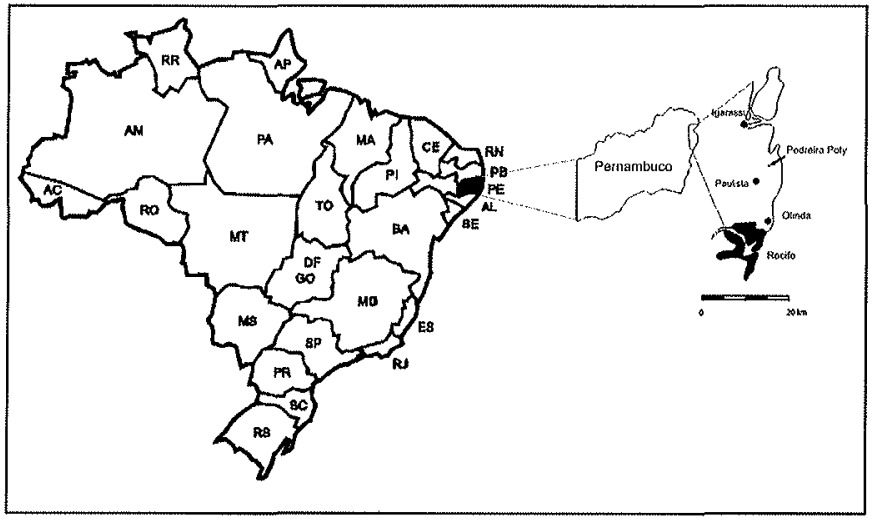

Figura 1- Mapa de localização do afloramento onde os crustáceos decápodes da Formação Maria Farinha foram coletados.

consiste basicamente em duas seções. A inferior, de pequena espessura, constituída por um calcário litográfico, com fósseis relativamente raros, esparsamente distribuídos, sem acumulações locais. A segunda seção, mais espessa, começa com calcários detríticos finos e puros, passando para calcários dolomitizados e calcários detríticos argilosos com intercalações de camadas de argila calcífera de reduzida espessura $(0,10 \mathrm{~m}$ a $0,25 \mathrm{~m})$. Esta seqüência se identifica com uma fase regressiva do mar após a transgressão gramame (Buerlen, 1959; Muniz, 1993). Aqui, os fósseis mostram as mesmas alterações rápidas que o caráter litológico. Há leitos estéreis e outros ricos em fósseis; há acumulações locais de conchas e leitos com abundância de fósseis em homogênea distribuição, sendo abundantes os moluscos e crustáceos.

White $(1887)$ e Maury $(1924,1930)$ descreveram o maior número de fósseis dessa unidade. Os demais elementos fossilíferos desta Formação foram descritos por Fernandes (1978corais), Buge \& Muniz (1974-briozoários), Penna-Neme \& Muniz (1976- escafópodes), Oliveira (1953-nautilóides), Tinoco (1963-esclerodermitos de holoturóides e placas de equinóides), Oliveira \& Santos (1969-biválvios), Muniz \& Ramirez (1977icnofósseis), Tinoco (1977-foraminíferos) e Dolianiti (1955-vegetais). Os fósseis mais característicos da Formação Maria Farinha são os nautilóides Cimonia pernambucensis e Hercoglossa lamegoi, bem como o gastrópode Campanile buarquianus, e o crustáceo Callianassa.

A referida unidade litoestratigráfica é do Paleoceno e representa um paleoambiente costeiro raso com variadas condições ecológicas, refletindo provavelmente movimentos oscilatórios da linha de costa (Beurlen, 1967). A idade atribuída foi baseada inicialmente em estudos geológicos e paleontológicos na localidade de Olinda, realizados por Oliveira \& Andrade Ramos (1956), onde foram levantadas detalhadas seções estratigráficas da formação, que foi então correlacionada ao Grupo Midway, da América do Norte, e Formação Soldado Rock de Trinidad, ambas de mesma idade, posteriormente confirmada por estudos subsequentes.

Os carbonatos da Formação Gramame estão sotopostos à Formação Maria Farinha, apresentando contato concordante. Segundo Feijó (1994), é interdigitada com a Formação Calumbi, e juntamente com as formações Gramame e Beberibe, a Formação Maria Farinha constitui um ciclo trangressivo-regressivo, com transgressão acelerada, seguida de um relativo período estável e finalizado por uma demorada regressão (Gallo et. al. 2001).

As amostras de crustáceos decápodes estudadas foram coletadas na pedreira da fábrica de cimento Poty, município de Paulista, Estado de Pernambuco- $8^{\circ} 6^{\prime} \mathrm{S}$ de latitude e $34^{\circ} 53^{\prime} \mathrm{W}$

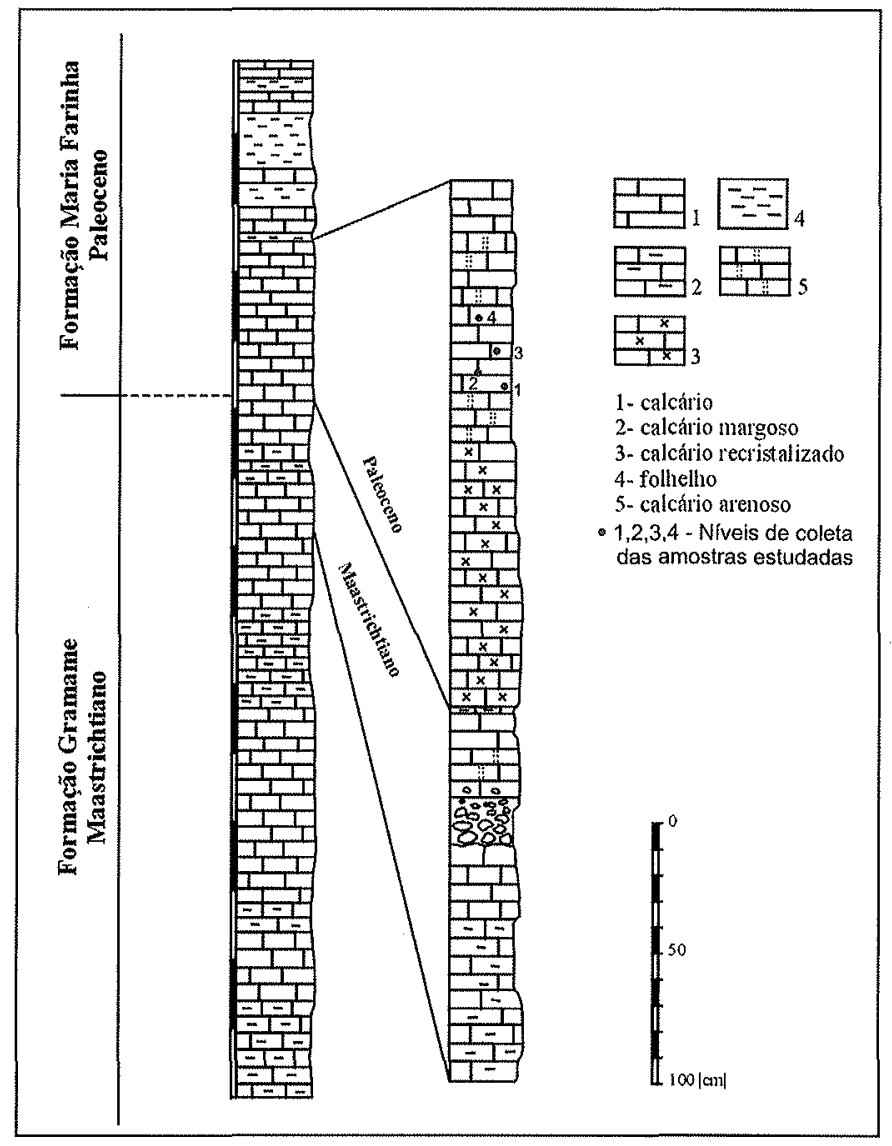

Figura 2- Coluna litoestratigráfica para a pedreira Poty (modificado de Stinnesbeck \& Keller, 1996).

de longitude, em cinco pontos dentro do pacote correspondente à microfácies biomicrito. (Figuras 1 e 2).

$O$ perfil estudado possui aproximadamente $14 \mathrm{~m}$ de altura, sendo que os primeiros $9,5 \mathrm{~m}$ inferiores correspondem à Formação Gramame, e o restante, à Formação Maria Farinha (Figura 2). Tanto a Formação Gramame quanto a Formação Maria Farinha se caracterizam por uma alternância de calcários finamente estratificados, calcários margosos e margas calcárias, intensamente bioturbados. O conteúdo carbonático dos sedimentos varia gradualmente, e as unidades litológicas são separadas por superfícies de erosão (Stinnesbeck \& Keller, 1996).

O conteúdo fossiliffero das duas unidades litoestratigráficas na seção estudada, é bem diferenciado. Enquanto nos sedimentos Gramame ocorrem cefalópodes amonóides, na Formação Maria Farinha, estes elementos são substituídos pelos nautilóides. Além disso, os biválvios e gastrópodes perfazem faunas distintas, tipicamente paleocênicas no pacote Maria Farinha (Beurlen, 1967).

O desaparecimento brusco e completo dos elementos cretácicos da Formação Gramame, bem como a mudança gradual de litologia, de calcário margoso para calcário puro detrítico, que reflete provavelmente uma rápida regressão do mar, reaparecendo uma fácies litorânea, são feições que indubitavelmente permitem separar as duas unidades litoestratigráficas ao longo do perfil, muito embora elas exibam uma transição gradativa.

BIOESTRATINOMIA O estudo bioestratinômico dos decápodes da Formação Maria Farinha, foi realizado por Távora e Miranda (2004) que trataram da coleta, análise e interpretação das feições tafonômicas macroscópicas (bioestratinômicas) de uma fáunula composta pelas espécies Necrocarcinus sp. e Cos- 
tacopluma nordestina Feldmann \& Martins-Neto, 1995.

Os crustáceos decápodes da Formação Maria Farinha estão preservados tridimensionalmente em calcários finos detríticos, sob a forma de restos inalterados e alterados por substituição (maioria), pouco fragmentados, com cerca de $10 \%$ de espécimes articulados (palma e dedos fixo e móvel). $\mathrm{Na}$ maior parte do material amostrado (90\%) os espécimes estão representados por tórax e dedos isolados. O tamanho dos indivíduos é aproximadamente semelhante para todos os representantes das espécies reconhecidas, sugerindo que os mesmo sofreram morte seletiva. Entretanto, exemplares fossilizados em posição de escape indica que houve soterramento de indivíduos ainda vivos, caracterizando elevada hidrodinâmica deposicional durante o evento de soterramento.

FOSSILDIAGÊNESE Durante a diagênese, as partes esqueletais dos organismos podem ser alteradas e substituídas em diferentes estágios, bem como sua química mineral original. As mudanças mais comuns ocorrem em bioclastos carbonáticos, onde conchas aragoníticas transformam-se em calcíticas, calcita alta magnesiana alteram-se para calcita baixa magnesiana, e todos estes polimorfos de carbonato de cálcio estão sujeitos a dissolução, silicificação, dolomitização e piritização. Em grãos esqueletais silicosos e fosfáticos as mudanças são mais sutis, porém também podem ser convertidos em calcita, dolomita, sílica e pirita (Tucker, 1991).

São analisados aqui os aspectos petrográficos e diagenéticos dos crustáceos decápodes, visando entendimento mais detalhado de sua história preservacional.

Análise petrográfica $\mathrm{O}$ exame petrográfico dos crustáceos decápodes e das rochas que os contém permitiu caracterizar uma microfácies deposicional, biomicrito (Folk, 1959), sem variações texturais e composicionais. São freqüentes constituintes alóquemes, representados por crustáceos decápodes, foraminíferos rotalídeos bentônicos e planctônicos, ostracodes, microbiválvios, microgastrópodes, algas calcárias, microbriozoários, corais, frústulas de diatomáceas cêntricas e, espinhos de equinóides (Figura 3a).

A matriz micrítica consiste em mosaicos uniformes de calcita microcristalina (menor do que 5 micrômetro de diâmetro)- micrita, apresentando-se localmente neomorfizada para bioesparito, assim como incipiente dolomitização. A paragênese diagenética compreende as seguintes fases sucessivas: 1) substituição da aragonita esqueletal por calcita (calcitizacão), 2) piritização da matéria orgânica, 3) fosfatização da matéria orgânica 4) compactação mecânica, 5) formação de franja de $\mathrm{CaCO}_{3}$ e 6) dissolução local de $\mathrm{CaCO} 3$ já precipitado nos poros.

Constituintes alóquemes As carapaças dos crustáceos decápodes são os constituintes alóquemes mais freqüentes, apresentando predominantemente composição carbonática, constituído por calcita prismática. Em muitos casos ocorre fosfatização parcial e total. Outros bioclastos também são freqüentes, representados por diversos grupos de microfósseis e fragmentos de macrofósseis. São reconhecidas tecas com arranjo unisserial, bisserial, planoespiral e trocoespiral de foraminiferos rotalídeos bentônicos e planctônicos, onde algumas câmaras apresentamse preenchidas por pirita, além de foraminiferos miliolídeos. Os ostracodes ocorrem como carapaça ovóide com parede fina preenchida por calcita. E também foram identificados fragmentos e conchas inteiras de microbiválvios e microgastrópodes, frústulas de diatomáceas cêntricas, algas calcárias, fragmentos longitudinais de zoécios de microbriozoários ciclostomados. De macrofósseis foram reconhecidos petrograficamente cálices de corais escleractíneos e, seções transversais elípticas com estruturas radiais e, longitudinais de espinhos de equinóides (Figura 4).

Fases diagenéticas As fases diagenéticas ocorreram possivelmente como processos interdependentes, e pelo menos em parte podem ter sido simultâneos.

1) Substituição da aragonita esqueletal por calcita A aragonita é uma forma metaestável de carbonato de cálcio, e é o composto mineralógico dos esqueletos dos decápodes da Formação Maria Farinha. O processo fossildiagenético inicia-se com a substituição da aragonita esqueletal por delgados filmes calcíti$\cos$, sendo preservados alguns cristais da estrutura esqueletal original muito comum em ambientes marinhos rasos, este processo denominado de calcitização, desencadeia-se a partir da ação de organismos endolíticos, tais como cianobactérias e fungos, que por vezes incrustam-se nas bordas dos bioclastos. Este conteúdo orgânico retém a aragonita original de maneira reliquiar, preservando as principais estruturas morfológicas dos bioclastos, cuja forma original foi mantida por terem sido envolvidos por envelopes micríticos. Os cristais neomórficos de calcita são anédricos e pseudopleocróicos (variando do incolor ao marrom pálido), em várias camadas lamelares e disseminados por toda a extensão dos bioclastos, embora concentrem-se em suas bordas e estruturas morfológicas mais proeminentes. Relações texturais permitem assumir que esta fase precedeu todas as demais. As carapaças de crustáceos decápodes apresentam cristais prismáticos de calcita em várias camadas lamelares (Figura $3 b$ ).

2) Piritização da matéria orgânica $O$ processo de piritização em fósseis ocorre em sedimentos marinhos de granulação fina, ricos em matéria orgânica, Carbono orgânico, Ferro e sulfato. Origina-se a partir da quebra da matéria orgânica (tecido animal) que desencadeia a sulfatoredução (2CH2O+SO42- $\rightarrow$ $\mathrm{H} 2 \mathrm{~S}+2 \mathrm{HCO} 3-)$ pelas bactérias, saturando as águas de percolação em monosulfetos de Ferro (FeS), que removem os íons de Hidrogênio, aumentando o $\mathrm{pH}$. O sulfeto dissolvido, produzido pela redução do sulfato reage com o elemento Enxofre, precipitando rapidamente sob a forma de pirita (FeS2) como mosaicos microcristalinos que retém indícios de sua estrutura interna ou como cristais euédricos. O Ferro necessário para a formação da pirita provém tanto da própria matéria orgânica, quanto das águas de percolação, disseminado por difusão (Raiswell, 1997, Tucker, 1991).

Trata-se de um processo precoce na história deposicional, que ocorre até no máximo poucos metros abaixo da superfície do substrato, em ambientes redutores com baixa circulação e condicões anóxicas, que favorecem a precipitação quase instantânea da pirita (Tucker, 1991).

Nos crustáceos decápodes estudados, o processo de piritização da matéria orgânica ocorreu de forma parcial e total. Na forma parcial a pirita ocorre como pequenos aglomerados arredondados e preenchendo carapaça de foraminíferos bentônicos e planctôni$\cos$, enquanto na forma total a pirita ocorre como manchas, preservando apenas o contorno dos bioclastos (Figura $3 \mathrm{c}$ ).

3) Fosfatização da matéria orgânica A precipitação de apatita está diretamente associada com a abundância de matéria orgânica e atividade bacteriana. O processo de fosfatização envolve uma série de variáveis, principalmente saturação da água do mar em relação ao íon $\mathrm{Ca}, \mathrm{pH}$ ácido e concentração de $\mathrm{PO} 4$ maior do que 0,1 ppm (Ames Jr, 1959). Uma solução fosfatizada infiltra-se nas carapaças dos fósseis, depositando-se em suas paredes internas.

$O$ processo de fosfatização ocorre sob a forma de substituição parcial ou total nos crustáceos decápodes. Esse processo ocorre formando películas amareladas ou acastanhadas sobre as 

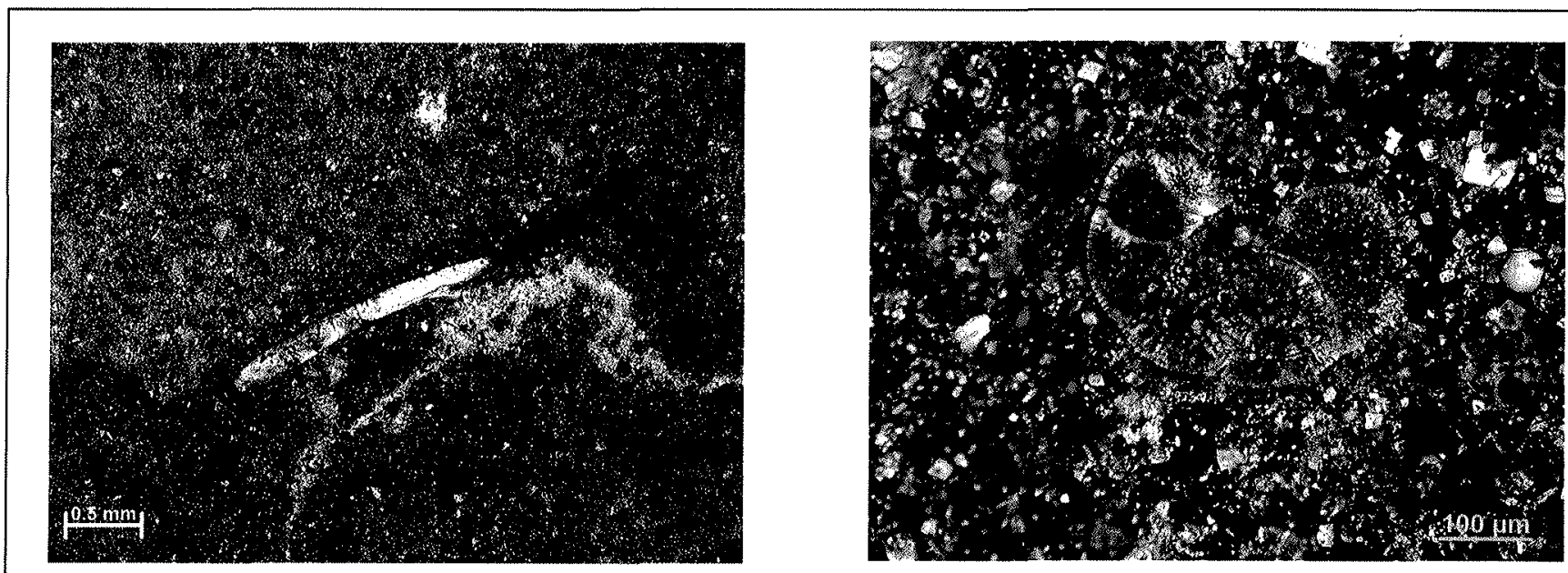

\section{A}
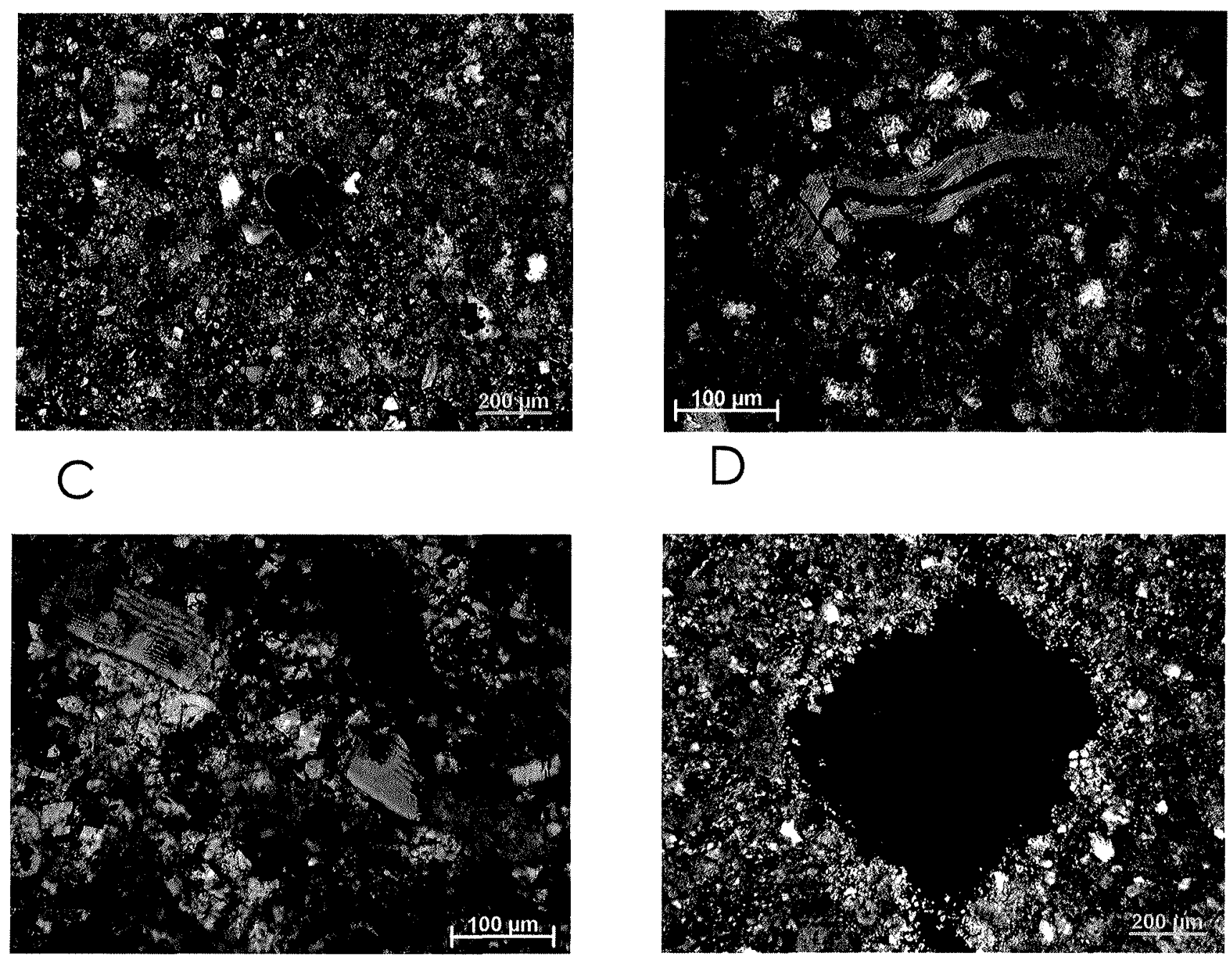

$\mathrm{E}$

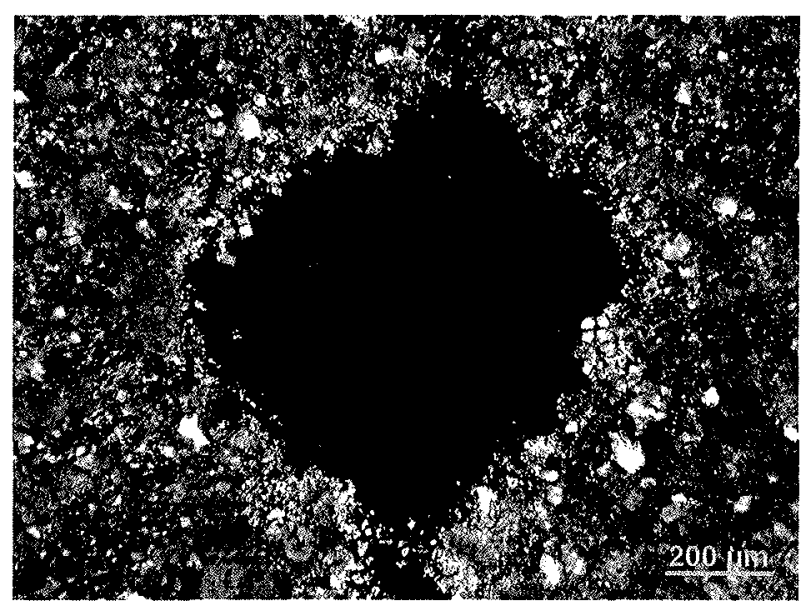

$\mathrm{F}$

Figura 3a Matriz micrítica localmente neomorfizada para bioesparito e, fragmento de carapaça de crustáceo decápode exibindo as camadas lamelares carbonáticas parcialmente fosfatizadas. Figura 3 b-Carapaça de foraminifero exibindo substituição da aragonita esqueletal por calcita, sob a forma de cristais anédricos e pseudopleocróicos concentrados principalmente nas bordas dos bioclastos. Figura 3c-Piritização total da carapaça de foraminifero planctônico, preservando apenas o contorno de sua carapaça. Figura 3d-Fragmento de carapaça de crustáceo decápode deformada por esforços de compactação mecânica, exibindo fosfatização sob a forma de películas acastanhadas sobre as camadas carbonáticas lamelares. Figura 3e- Fragmento de carapaça de crustáceo decápode quebrado em duas partes, devido á compactação mecânica sofrida pelo bioclasto durante a fossildiagênese. Figura $3 f$-Anel da borda de um poro mostrando a formação da franja de carbonato de cálcio e a dissolução local desta franja. 

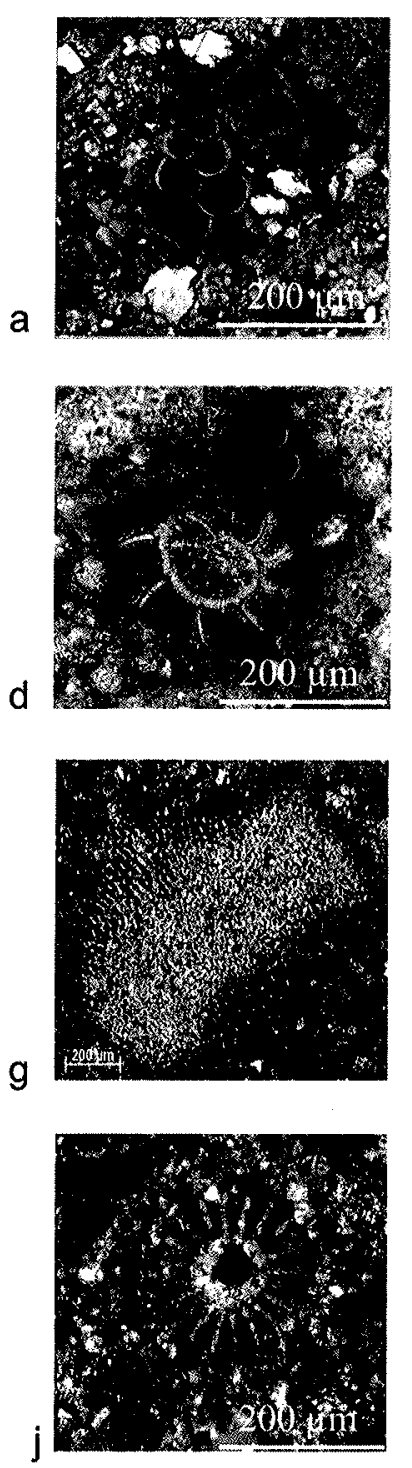

$\mathrm{m}$

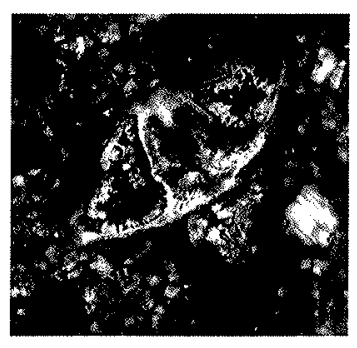

$p$

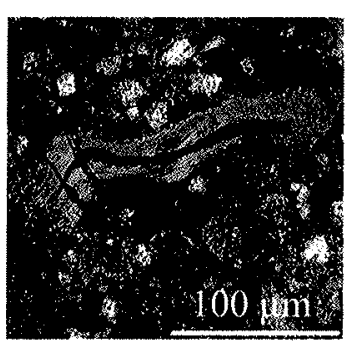

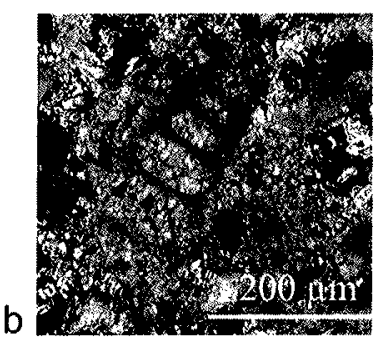
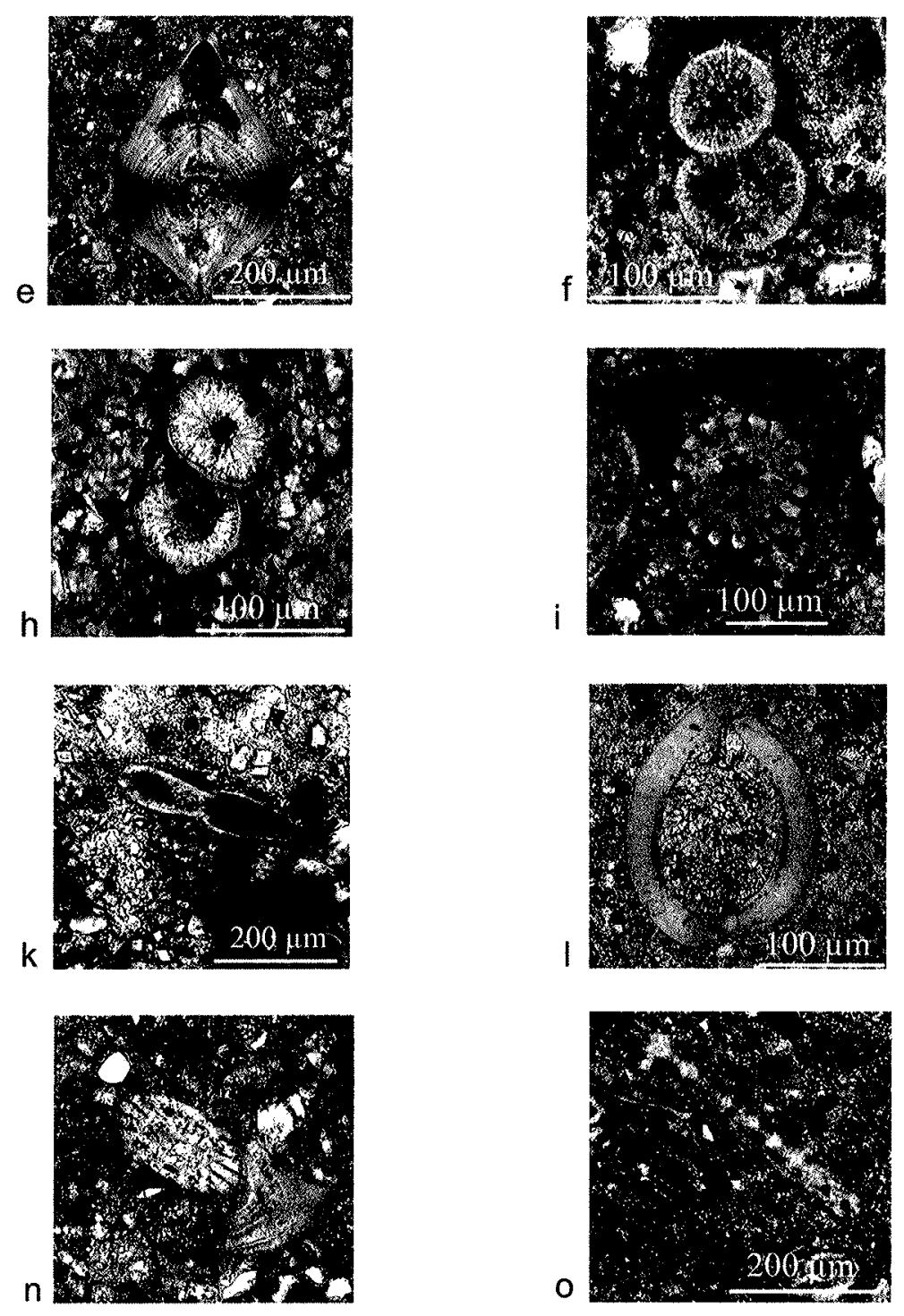

Figura 4- Constituintes alóquemes do biomicrito: (a) foraminifero rotalídeo bisserial bentônico; (b) foraminifero rotalideo unisserial bentônico; (c) foraminifero rotalídeo planoespiral bentônico; (d) foraminifero rotalídeo planoespiral bentônico ornamentado por espinhos; (e) foraminifero miliolideo; (f) foraminifero rotalideo trocoespiral planctônico; $(\mathrm{g})$ alga calcária; (h) diatomáceas cêntricas; ( $i)$, (j) seção transversal de cálice de coral escleractíneo; (k) seção longitudinal de briozoário ciclostomado; (l) microbiválvio; (m) microgastrópode; (n) seção transversal de espinho de equinóide regular; $(o)$ seção longitudinal de espinho de equinóide regular; (p) fragmento de carapaça de crustáceo decápode; (q) ostracode. 


\begin{tabular}{|c|c|c|c|c|c|c|}
\hline $\begin{array}{l}\text { Ref } \\
\text { amostras }\end{array}$ & $\mathrm{SiO}_{2}(\%)$ & $\mathrm{Al}_{2} \mathrm{O}_{3}(\%)$ & $\begin{array}{l}\text { Ferro/otal } \\
(\%)\end{array}$ & $\mathrm{TiO}_{2}(\%)$ & $\begin{array}{l}\text { Perda ao } \\
\text { Fogo (\%) }\end{array}$ & $\mathrm{POO}^{\circ} \%$ \\
\hline $\mathrm{MF}-\mathrm{l}$ & 15,76 & 6,00 & 1,63 & $<0,10$ & 32,98 & 0,27 \\
\hline$M F-2$ & 9,84 & 3,86 & 0,92 & $<0,10$ & 13,19 & 25,21 \\
\hline $\mathrm{MF}-3$ & 4,25 & 2,71 & 0,83 & $<0,10$ & 37,23 & 0,29 \\
\hline$M F-4$ & 18,33 & 5,37 & 2,71 & 0,18 & 31,52 & $<0,10$ \\
\hline MF-S & 23,86 & 9,11 & 3,45 & 0,20 & 27,94 & $<0,10$ \\
\hline MF -6 & 15,13 & 6,02 & 2,47 & $<0,10$ & 34,07 & $<0,10$ \\
\hline MF-7 & 26,47 & 8,11 & 2,99 & 0,20 & 27,41 & $<0,10$ \\
\hline $\mathrm{MF}-8$ & 20,33 & 6,59 & 2,35 & $<0,10$ & 30,53 & $<0,10$ \\
\hline$M F-9$ & 7,18 & 2,86 & 0,80 & $<0,10$ & 29,20 & 9,55 \\
\hline$M F-10$ & 3,55 & 2,94 & 0,61 & 0,27 & 30,38 & 9,98 \\
\hline
\end{tabular}

Figura 5-Resultados das análises químicas dos óxidos de SiO2, Al2O3, TiO2, Ferro total e perda ao fogo nas rochas e fragmentos de carapaças de crustáceos decápodes da Formação Maria Farinha.

camadas de lamelas carbonáticas (Figura 3d).

4) Compactação mecânica A compactação mecânica é observada principalmente nas carapaças dos decápodes, que exibem tanto fragmentos quebrados quanto deformados por esforços mecânicos compressionais (Figuras $3 \mathrm{~d}$ e $3 \mathrm{e}$ ). Através de relações texturais observa-se que essa compactação ocorreu anteriormente a precipitação de $\mathrm{CaCO} 3$, já que nas zonas de quebras ocorrem aglomerados de carbonato de cálcio.

5) Formação de Franja O processo de formação de franja ocorre após a quebra dos bioclastos, preenchendo as bordas dos espaços vazios produzidos pela compactação mecânica (Figura 3f).

6) Dissolução local do $\mathrm{CaCO} 3$ já precipitado nos poros. A dissolução de carbonato de cálcio ocorre localmente nos poros onde foi depositado como franja, nos espaços originados a partir da fase quatro ( Figura 3f).

\section{GEOQUÍMICA}

Difratometria de raios-X Através dos estudos realizados por difração de raios- $X$, foi revelada a composição mineralógica abaixo discriminada. As carapaças dos crustáceos decápodes são constituídas por calcita microcristalina, enquanto que nas rochas que os contém foram identificados os demais minerais, além da forma estável do carbonato de cálcio.

$\begin{array}{ll}\text { Quartzo_} & \mathrm{SiO} 2 \\ \text { Calcita_} & (\mathrm{Ca}, \mathrm{Mg}) \mathrm{CO} 3 \\ \text { Hidroxilapatita } & \mathrm{Ca} 5(\mathrm{OH})(\mathrm{PO} 4) 3 \\ \text { Dolomita } & \mathrm{CaMg}(\mathrm{CO} 3) 2 \\ \text { Caolinita } & \mathrm{Al} 2 \mathrm{Si} 2 \mathrm{O} 5(\mathrm{OH}) 4 \text { (traço) }\end{array}$

Análise química quantitativa Durante a diagênese a química dos elementos maiores, traços e as assinaturas isotópicas são comumente alteradas. Em esqueletos carbonáticos os elementos medidos freqüentemente são $\mathrm{Mg}, \mathrm{Sr}, \mathrm{Na}, \mathrm{Fe}, \mathrm{Mn}$ e os isótopos estáveis de Oxigênio e Carbono. Os valores obtidos são importantes indicadores paleoambientais porque a composição química dos esqueletos carbonáticos é um reflexo das condições ambientais, principalmente química da água e temperatura ( $\mathrm{Tu}-$ cker, 1991).

Foram realizadas análise químicas de seis elementos maiores (óxidos), Ferro Total, um elemento traço e perda ao fogo de dez amostras selecionadas. Em geral são observados valores com poucas variações dos teores dos elementos químicos maiores.

Os calcários impuros dolomitizados (índices de $\mathrm{MgO}$ variando entre $0,63 \%$ e $7 \%$ ), mostram valores de $\mathrm{CaO}$, situados entre $35,54 \%$ e $50,58 \%$, os de perda ao fogo, entre $13,19 \%$ e $34,07 \%$, e porcentagens de $\mathrm{SiO} 2$, oscilando entre $4,25 \%$ e $26,47 \%$, atestam que os calcários tiveram um relativo influxo de terrígenos. Esta influência continental no entanto, pode ser considerada relevante, quando analisados os valores de $\mathrm{TiO} 2$, menores que $0,1 \%$, em sete amostras analisadas, e variando entre $0,18 \%$ e $0,27 \%$ em outras três, sugerindo proximidade ao continente, já que o titânio ocorre como elemento traço na água do mar.

As análises dos teores de Ferro total apresentam o valor mais elevado, 3,45\%, na amostra MF-5, cujo exame sob microscópio de luz refletida, revelou a ocorrência do mineral pirita, o que sugere processo de piritização da matéria orgânica. Os mais significativos valores de P2O5 (componente principal das apatitas microcristalinas) foram encontrados em três amostras, variando entre $9,98 \%$ e $25,21 \%$, enquanto nas demais estes valores são menores que $0,1 \%$. Esta grande variação pode estar relacionada a um processo de fosfatização da matéria orgânica (hidroxilapatita), macroscopicamente sugerido pela coloração esbranquiçada das carapaças, e ao microscópio petrográfico por películas superficiais de coloração acastanhada.

O Manganês ocorre na estrutura da calcita, substituindo o Cálcio. Os seus teores tendem a subir, à medida que também sobem os valores de Ferro total, já que em domínio diagenético é comum o Ferro acompanhar o Manganês, devido serem adicionados às conchas durante a diagênese por meio dos fluidos intersticiais.

Análise dos isótopos estáveis de Carbono e Oxigêno Os valores de $\delta 180$ dentro do intervalo entre $-4 \%$ e $2 \%$, demonstram que as conchas dos organismos foram precipitadas em equilíbrio isotópico com as águas de seus ambientes de vida, e estão diretamente ligados à temperatura das mesmas. Estes valores são similares aos precipitados abiogênicos dos oóides e cimentos marinhos. As razões isotópicas de $\delta 13 \mathrm{C}$, ao contrário, não são influenciadas pela temperatura, e o seu equilíbrio isotópico com o ambiente é atestado quando os valores estão entre são $0 \% 0$ $2 \%$. O desequilíbrio ocorre devido a mistura e troca isotópica entre o $\mathrm{CO} 2$ da água do mar e o $\mathrm{CO} 2$ oriundo do processo respiratório dos organismos, normalmente com baixos teores de 180 e 13C no seu sítio de precipitação esqueletal ou bem próximo dele (Tucker, 1991).

Utilizando espectômetro de massa de fonte gasosa Finnigan MAT 252, acoplado a um sistema KIEL-III de extração on line de $\mathrm{CO} 2$, foram efetivados estudos isotópicos de Carbono e Oxigênio em fragmentos de cinco carapaças de crustáceos decápodes da Formação Maria Farinha, sendo três (MF-1, MF-2 e MF3) de Costacopluma nordestina, um (MF-4) de Necrocarcinus sp. e outro (MF-5) de Glyphithyreus sturgeoni. Os valores de $\delta 13 \mathrm{C}$ variaram entre $-0.81 \%$ e $-2,22 \%$, enquanto os de $\delta 18 \mathrm{O}$ oscilaram entre $-2,83 \%$ e $-3,91 \%$ (Figura 7 ). Os valores negativos de $\delta 13 \mathrm{C}$ indicam oxidação da matéria orgânica no benthos e podem representar períodos de rebaixamento do nível do mar. Os valores negativos de $\delta 180$, embora atestem equilíbrio isotópico, podem refletir efeitos da diagênese associados com a exposição da plataforma carbonática, em períodos de nível do mar mais baixo. $\mathrm{O}$ ambiente deposicional da Formação Maria Farinha, costeiro com oscilações do nível do mar, viabiliza a possibilidade supracitada para os valores de $\delta 180$, já que nesse 


\begin{tabular}{|c|c|c|c|}
\hline $\begin{array}{c}\text { Ref } \\
\text { amostras }\end{array}$ & CaO (\%) & $\mathrm{MgO}(\%)$ & $\mathrm{Mn}(\mathrm{ppm})$ \\
\hline MF-1 & 38,97 & 1,41 & 130 \\
\hline MF-2 & 43,51 & 0,63 & 97 \\
\hline MF-3 & 50,58 & 1,51 & 165 \\
\hline MF-4 & 35,54 & 2,61 & 158 \\
\hline MF-5 & 25,19 & 5,73 & 185 \\
\hline MF-6 & 32,60 & 7,00 & 272 \\
\hline MF-7 & 27,00 & 5,09 & 171 \\
\hline MF-8 & 33,58 & 3,24 & 158 \\
\hline MF -9 & 47,57 & 1,04 & 171 \\
\hline MF - 10 & 50,09 & 0,84 & 201 \\
\hline
\end{tabular}

Figura 6- Resultados das análises quimicas por absorção atômica dos óxidos de $\mathrm{CaO}, \mathrm{MgO}$, e do elemento traço Manganês nas rochas e fragmentos de carapaças de crustáceos decápodes da Formação Maria Farinha.

ambiente a grande influência continental também é registrada nos valores isotópicos, pois ocorre empobrecimento de 180 e enriquecimento de 160 (mais abundante em domínio conti-nental). Assim, os eventos negativos nos isótopos de Carbono e Oxigênio e suas variações numéricas, sugerem paleoambiente costeiro.

Estes dados geoquímicos são compatíveis com o ambiente deposicional atribuído para a Formação Maria Farinha, como costeiro raso, já que a influência continental está evidenciada no aspecto impuro dos calcários e sua dolomitização, bem como nos valores dos isótopos $\delta 13 \mathrm{C}$ e $\delta 180$, coerentes com as evidências sedimentológicas, paleontológicas e tafonômicas.

IMPLICAÇÕES PALEOAMBIENTAIS Os crustáceos decápodes da Formação Maria Farinha são típicos de ambientes costeiros tropicais a temperados de baixa energia. Segundo Beurlen (1959) as características geológicas e paleontológicas atestam para os estratos desta unidade litoestratigráfica, deposição em ambiente marinho costeiro com oscilações do nível do mar. A Formação Maria Farinha foi depositada durante um evento de regressão, com aumento de energia e redução de lâmina d'água, que provocou variações laterais em sua faciologia (Barbosa et al, 2003). Seu ambiente deposicional pode ser definido como de plataforma interna a infralitoral, incluindo proximidade de estuários (Barbosa et al, op.cit.). Os braquiúres estudados por Feldmann \& Martins Neto (1995), Távora \& Miranda (2004) e Távora et al (2005), correspondem aos atuais goneplacídeos e ocipodídeos, típicos de áreas costeiros restritos, os mangues, bem como aos calianassídeos recentes, que vivem em todos os subambientes litorâneos. Segundo Barbosa et al (2003), a pedreira Poty representa uma transição gradual dos carnonatos

\begin{tabular}{|c|c|c|c|}
\hline $\begin{array}{c}\text { Ref. } \\
\text { amostras }\end{array}$ & $\delta^{13} \mathrm{C}$ & $\delta^{18} \mathrm{O}$ & Expansão \\
\hline $\mathrm{MF}-1$ & $-0,81$ & $-2,83$ & - \\
\hline $\mathrm{MF}-2$ & $-1,71$ & $-3,73$ & - \\
\hline $\mathrm{MF}-3$ & $-1,55$ & $-3,91$ & - \\
\hline $\mathrm{MF}-4$ & $-2,11$ & $-3,74$ & - \\
\hline $\mathrm{MF}-5$ & $-2,22$ & $-3,86$ & - \\
\hline
\end{tabular}

Figura 7-Resultado das análises isotópicas de Carbono e Oxigênio ( $\delta 13 \mathrm{C}$ e $\delta 180$ ) em fragmentos de carapaças de crustáceos decápodes da Formação Maria Farinha.

para margas, e por fim um maior influxo de elementos siliciclásticos. As microfácies esparito, microesparito recristalizado com dolomita, bioesparitos e biomicritos, dentro do pacote correspondente à Formação Maria Farinha, indicam o incremento de regressão marinha com maior aporte terrígeno. As diferentes litofácies representam diferentes estágios de pulsos regressivos influenciados pela ação de eventos tectônicos.

As feições bioestratinômicas reconhecidas nos elementos da carcinofáunula por Távora \& Miranda (2004), sugerem morte seletiva, onde restos de indivíduos juvenis e senis mostram-se dominantemente fragmentados e desarticulados. Sua preservação tridimensional, cujas partes morfológicas dispõem-se caoticamente em relação à matriz, sugere baixo grau de retrabalha.mento e acentuada seleção hidráulica ocorrida em um momento de elevada energia no ambiente deposicional durante o evento de soterramento.

$\mathrm{O}$ exame fossildiagenético permitiu caracterizar seis fases diagenéticas interdependentes, sindeposicionais e provavelmente simultâneas, cujas feições reconhecidas torna possível detalhamento da dinâmica deposicional em seu ambiente de vida.

A calcitização, piritização e fosfatização da matéria orgânica reconhecidas no material estudado sugerem condições redutoras no ambiente deposicional, pelo menos no início do sepultamento, que fossilizaram-se rapidamente. A presença de pirita indica estágio eodiagenético provocado pelo soterramento de matéria orgânica durante eventos episódicos de alta energia ou ocorrência de microambientes anóxicos, ou ainda eventuais restrições de oxigenação. A quebra dos bioclastos está relacionada com a pressão dos gases gerados e liberados pela decomposição por atividade microbiana, também ocorrida em ambiente redutor. Nas últimas fases diagenéticas os teores de ferro total atestam oxidação no ambiente deposicional.

Confrontando os dados paleoambientais existentes (Beurlen, 1959, 1967; Távora \& Miranda, 2004) com os aqueles aqui levantados, corrobora-se que a fragmentação e desarticulação dos decápodes ocorreram em um período mais agitado no ambiente deposicional. A acumulação, deposição, sepultamento e a fossilização propriamente dita ocorreram nos períodos de relativa calma no ambiente deposicional. As condiçôes redutoras do meio, caracterizadas pelas feições de piritização e fosfatização da matéria orgânica, bem como a compactação mecânica, corro- 
boram condições de ambiente calmo e restrito.

De acordo com as informações listadas acima pode-se supor que o ambiente deposicional da Formação Maria Farinha oscilavam entre litorâneo, nos períodos transgressivos, e de mangue nos períodos regressivos. Essas condições de ambiente de mangue também são corroboradas a partir dos dados obtidos com as análise químicas quantitativas, principalmente dos óxidos $\mathrm{SiO} 2$ e TiO2, além de $\mathrm{CaO}, \mathrm{MgO}$, Ferro total e $\mathrm{Mn}$. O caráter impuro e a dolomitização dos biomicritos, bem como os valores negativos obtidos nas análises isotópicas de Carbono e Oxigênio, são indicadores de grande aporte terrígeno no ambiente deposicional, porque os resultados das análises efetuadas mostram grande interferência da crosta continental nos teores dos óxidos analisados, corroborando assim a interpretação gerada a partir dos dados paleontológicos e bioestratinômicos. Também os valores de $\mathrm{Mg}$, Ferro total, $\mathrm{Mn}, \delta 13 \mathrm{C}$ e $\delta 18 \mathrm{O}$, são coerentes com a alteração da química dos elementos esqueletais de composição aragonítica por calcificação.

Agradecimentos Os autores agradecem ao Departamento de Geologia da Universidade Federal de Pernambuco, pela cessão de amostras, Pablo Simões Martins, pelas análises isotópicas e também aos revisores da RBG.

\section{Referências}

Albertão, G.A., Koutsoukos, E.A.M., Regali, M.P.S., Attrep Jr., M. \& Martins Jr. P.P. 1993. The Cretaceous Tertiary boundary (KTB) at Pernambuco/Paraíba basin, Northeastern Brazil. Acta Geologica Leopoldensia, 16 (38): 59-71.

Albertão, G.A., Regali, M.P.S., Koutsoukos, E.A.M. \& Martins Jr. P.P. 1994. O registro micropaleontológico, com base em foraminíferos e palinomorfos, no limite Cretáceo-Terciario (K-T), bacia de Pernambuco-Paraiba (PE/PB), Nordeste do Brasil - Inferências paleoambientais. Acta Geologica. Leopoldensia, 39 (1): 131-145.

Ames Jr, L.L.1959. The genesys of carbonate apatites. Economic Geology, 4 (54): 829-841.

Barbosa, J.A., Souza, E.M., Lima Filho, M.F. \& Neumann V.H. 2003. A estratigrafia da Bacia Paraíba: uma reconsideração. Estudos Geológicos, 13: 89-108.

Beurlen, K.1959. Observações sobre a Formação Maria Farinha, Estado de Pernambuco. Arquivos de Geologia, Universidade do Recife, 1: 5-16.

Beurlen, K. 1967. Paleontologia da faixa costeira Recife-João Pessoa. Boletim da Sociedade Brasileira de Geologia, 16 (1): 73-79.

Biffar, T.A. 1971. The genus Calianassa (Crustacea, Decapoda, Thalassinidea) in South Florida, with keys to the western Atlantic species. Bulletin of Marine Science, 21 (3): 637- 715.

Biffar, T.A. \& Provenzano Jr A.J. 1972. A reexamination of Dardanus venosus (H. Milne-Edwards) and D. imperator (Miers), with a description of a new species of Dardanus from the western Atlantic (Crustacea, Decapoda, Diogenidae). Bullettin of Marine Science, 22 (4): 777- 805 .

Buge, E. \& Muniz G.C.B. 1974. Lunulites (Heteractis) barbosae, nouvelle spéce de bryozoaire lunulitiforme (Bryozoa, Cheilostomata) du Paléocène du Nord. Est. Du Brésil. Annales Paléontologie (Invertebrés), 60 (2): 191-202.

Dolianiti, E. 1955. Frutos de Nipa no Paleoceno de Pernambuco, Brasil. Rio de Janeiro, Departamento nacional da Produção Mineral / Divisão de Geologia e Mineralogia, 36p. (Boletim 158).

Feijó, F.J. 1994. Bacia de Pernambuco-Paraíba. Boletim de Geociências da PETROBRÁS, 8 (1): 235-245.

Feldmann, R. M. \& Martins-Neto R. G. 1995. Costacopluma nordestina n. sp. (Decapoda: Retroplumidae) from the Maria Farinha formation (Paleocene) of Brasil. Jornal of Paleontology, 69 (3): 610- 61.

Feldmann, R.M., Bice, K.L., Hopkins, C.S., Salva, E.W. \& Pickford K. 1998. Decapod Crustaceans from the Eocene Castle Hayne Limestone, North Carolina: paleoceanographic implications. Journal of Paleontology, 72 (1), The Paleontological Society Memoir 48, 1-28 (supplement).

Fernandes, A.C. S. 1978. Corais Hermatípicos da Formação Maria Farinha, Paleoceno do Estado de Pernambuco. In: CONGRESSO BRASILEIRO DE GEOLOGIA, 30, 1978. Anais, Recife, SBG, v. 2, p. 960-964.

Folk, R. L. 1959. Practical petrographic classification of limestones. Bulletin of American Association Petroleum Geologists, 43; 1-38.

Gallo, V., Figueiredo, F.J., Carvalho, L.B. \& Azevedo S.A.K. 2001 Vertebrate assemblage from the Maria Farinha Formation after the K-T boundary. News Jahrbuch Fur Geologieb and Palaeontologie Abhandlunger. 219: 261-284. Stuttgart.

Mabesoone, J.M. , Tinoco, I.M. \& Coutinho P.N. 1968. The MesosoicTertiary boundary in Northeastern Brazil. Palaeogeography, Palaeoclimatology, Palaeoecology, 4: 161-185.

Maury, C.J. 1924. Fósseis Terciários do Brasil. Serviço Geológico e Mineralógico do Brasil, Monografia 4: 460468.

Maury, C.J. 1930. O Cretáceo da Parahyba do Norte. Serviço Geológico e Mineralógico do Brasil, Monografia 8: 1-350.

Milne-Edwards, A.1860. Monographie des décapodes macrures fossiles de la famille des thalassiniens. Annales of Science Natural, Zoologie, ser.4, 14: 129- 293.

Muniz, G.C.B. 1993, Novos moluscos da Formação Gramame, Cretáceo Superior dos estados da Paraíba e de Pernambuco, Nordeste do Brasil. Publicação Especial do Departamento de Geologia, Centro Tecnológico, Universidade Federal de Pernambuco. 1: 1-202.

Muniz, G.C.B. \& Ramirez L.V.O. 1977. Observações ichnológicas preliminares na Formação Maria Farinha, Paleoceno do Nordeste. In: SIMPÓSIO DE GEOLOGIA DO NORDESTE, 8, 1977. Atas, Campina Grande, SBG-Núcleo Nordeste, p.111-119.

Oliveira, P.E. 1953. Invertebrados fósseis da Formação Maria Farinha. I- Cephalopoda. Rio de Janeiro, Departamento Nacional da Produção Mineral/ Boletim da Divisão de Geologia e Mineralogia, 33p. (Boletim 146).

Oliveira, P.E. \& Andrade Ramos J.R. 1956. Geologia das Quadrículas de Recife e Pontas de Pedra. Rio de Janeiro, Departamento Nacional da Produção Mineral / Boletim da Divisão de Geologia e Mineralogia, Departamento Nacional de Produção Mineral, 60p. (Boletim 151).

Oliveira, P.E. \& Santos M.E. 1969. Invertebrados Fósseis da Formação Maria Farinha: Bivalvia. Sociedade Brasileira de Geologia, Núcleo da Bahia, 60p. (Boletim 1). 
Penna-Neme, L. \& Muniz G.C.B. 1976. Um novo Dentalium (Mollusca-Scaphopoda) da Formação Maria Farinha, Paleoceno de Pernambuco. Anais da Academia Brasileira de Ciências, 48 (3): 523 525 .

Raiswell, R.1997. A geochemical framework for the application of stable sulphur isotopes to fossil pyritization. Journal of the Geological Society of London, 154: 343-356.

Rodrigues, S.A.1978. Ctenocheles holthuisi (Decapoda, Thalassinidea), a new remarkable mud shrimp from the Atlantic Ocean. Crustaceana, 34 (2): 113- 120.

Saussure, H. 1858. Mémoire sur divers Crustacés nouveaux du Mexique et dês Antilles. Societe Physique et d' Histoire Naturelle de Genève, Memoires, 14 (2): 417-496.

Say, T. 1817-1818. An account of the Crustacea of the United States. Journal of the Academy of Natural Sciences of Philadelphia, 1 (1): 57-169, 2: 235-458.

Stinnesbeck, W. \& Keller G. 1996. Environmental changes across the Cretaceous-Tertiary boundary in northeastern Brazil. In: Keller, G. \& MacLeod, N. (eds.), Cretaceous-Tertiary mass Extinction: Biotic and Environmental Changes, $2^{\circ}$ Edição, New York, p. 451-469.
Távora, V. A. \& Miranda M.C. C. 2004. Sistemática e Tafonomia de uma Fauna de Crustáceos Decápodes da Formação Maria Farinha (Paleoceno), Estado de Pernambuco, Brasil. Revista Brasileira de Paleontologia, 7: 4552

Távora, V.A., Miranda, V.F.O., Viegas, L.G.F. \& Galvão P.H.F. 2005. Novos registros de crustáceos decápodes do Cenozóico (Paleoceno e Mioceno Inferior). Revista Brasileira de Geociências, 35 (3): 393-400.

Tínoco, I.M. 1963. Fragmentos de equinodermas do Paleoceno de Pernambuco. Arquivos de Geologia, Escola de Geologia, Universidade do Recife, 4: 49-63.

Tinoco, I.M. 1977. Foraminíferos bentônicos da Formação Maria Farinha (Paleoceno de Pernambuco). In: SIMPÓSIO DE GEOLOGIA DO NORDESTE, 8, 1977. Atas, Campina Grande, SBG-Núcleo Nordeste, p. 6569 .

White, C. 1887. Contribuições à Paleontologia do Brasil. Archivos do Museu Nacional, 7: 1-273.

Manuscrito NB-0061

Revisão aceita em 23 de julho de 2006 
Fossildiagênese e geoquímica dos crustáceos decápodes da formação maria farinha (paleoceno), estado de Pernambuco, Brasil 